\section{AB1355-HPR A SYSTEMATIC LITERATURE REVIEW (SLR) ON NURSING SENSITIVE OUTCOMES IN SYSTEMIC SCLEROSIS (SSC)}

Khadija El Aoufy, Laura Rasero, Guya Piemonte, Gianni Virgili, Serena Guiducci, Cosimo Bruni, Silvia Bellando Randone, Marco Matucci-Cerinic. University of Florence, Florence, Italy

Background: SSc affects significantly patients' functionality and Quality of Life (QoL). Specific Nursing Sensitive Outcomes (NSOs) still need to be established in SSc.

Objectives: This SLR was aimed at identifying NSOs in SSc patients and the related screening tools.

Methods: Medline, CINHAL, EMBASE and PsycINFO were searched to identify relevant studies. Experimental and observational studies that reported nursing interventions and NSOs were included. All potentially eligible studies were read in full text and examined against the selection criteria previously listed. Quality assessment was carried out through Critical Appraisal Skills Programme tools; and, the OMERACT (Outcome Measures in Rheumatology) comprehensive conceptual framework for health was used to contextualise and summarize findings.

Results: 7015 records were screened for title and abstract, 39 full-text were identified and assessed. Eleven studies were included in this SLR. For the core area "pathophysiological manifestations" 4 domains (health's status, digital ulcers, clinical efficacy and fatigue), and, for the core area"impact on life"- 5 domains were found (functionality, patient knowledge, patient satisfaction, psychological status and quality of life). Thus, NSOs identified were physical function and parameters, health events, upper limb functionality, patient's knowledge of disease complications, degree of self-management, need for nursing instructions, self-efficacy, health efficacy, psychological state, depressive mood and QoL.

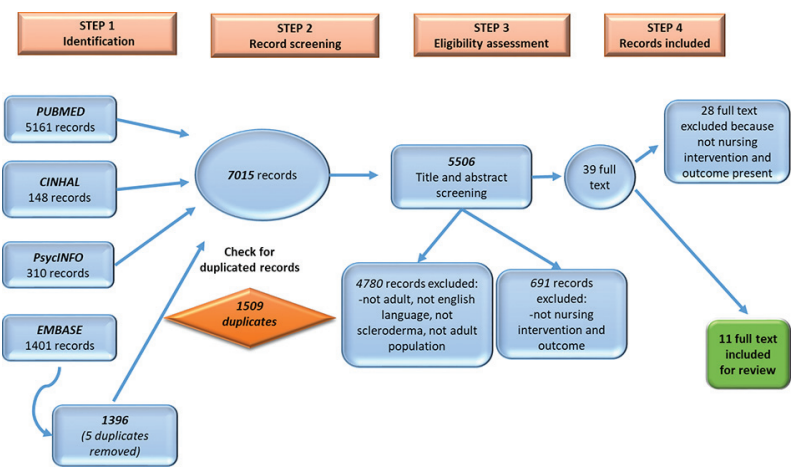

Figure 1

Conclusion: The results identify outcomes that may allow the structuring of a preliminary behavioural flow chart for nursing SSc case management. Further researches are warranted to examine the multidimensional and complex role of nursing in SSc management.

Flow chart of the SLR:
Disclosure of Interests: Khadija El Aoufy: None declared, Laura Rasero: None declared, Guya Piemonte: None declared, Gianni Virgili: None declared, Serena Guiducci: None declared, Cosimo Bruni: None declared Silvia Bellando Randone: None declared, Marco Matucci-Cerinic Grant/ research support from: Actelion, MSD, Pfizer, BMS, Chemomab, Sanipedia, Speakers bureau: Actelion, BMS; MSD, Janssen

DOI: 10.1136/annrheumdis-2019-eular.7685

\section{AB1356-HPR PHYSICAL ACTIVITY BEFORE, DURING AND AFTER PREGNANCY IN WOMEN WITH SPONDYLOARTHRITIS - DATA FROM REVNATUS}

Bente Jakobsen, Hege Svean Koksvik. St. Olavs hospital, Trondheim University Hospital, Norwegian National Advisory Unit on pregnancy and rheumatic diseases, Trondheim, Norway

Background: There are no known studies on physical activity (PA) in pregnancy for women with spondyloarthritis (SpA).

$\mathrm{PA}$ is an essential and well-documented part of treatment for SpA [1] The Norwegian Mother and Child Cohort Study (MoBa) found that established regular exercise routines pre-pregnancy was the strongest correlate of regular exercise during pregnancy [2].

A Swedish study of patients with SpA has shown that only 7 out of 10 patients with SpA meet the World Health Organization (WHO) recommendations of PA [3]. In MoBa $46.4 \%$ were regular exercisers $(\geq 3$ times a week) before pregnancy, while $25 \%$ were non-exercisers $(\leq 3$ times a month). At pregnancy week $17,28 \%$ were regular exercisers, and $41 \%$ were non-exercisers.By pregnancy week 30 , only $20 \%$ were still regular exercisers and $53 \%$ were non-exercisers [2]

Objectives: To describe the level of PA before, during and after pregnancy for Norwegian women with SpA.

Methods: Women with SpA (ICD-10 M45, M46.1, M46.8 and M46.9) enrolled in the Norwegian nationwide quality register RevNatus that have self-report their level of PA, are included. Data from seven time points are presented.

Results: BASDAI - Bath Ankylosing Spondylitis Disease Activity Index, BMI body mass index, VAS - visual analogue scale

Conclusion: During pregnancy, the percentage of women with $\mathrm{SpA}$ in the non-exercising group are increasing. The percentage of regular exercisers is lower 12 months after delivery than pre-pregnancy. Throughout the seven time points, $68-91 \%$ of the women with SpA do not fulfil the WHO recommendations for PA.

PA should be an integral part of standard care throughout the course of disease for people with SpA and healthcare providers should take responsibility for promoting it and make necessary referrals to ensure that people with SPA receive appropriate PA-interventions [1].

\section{REFERENCES}

[1] Rausch Osthoff, A.K., et al., 2018 EULAR recommendations for physical activity in people with inflammatory arthritis and osteoarthritis. Ann Rheum Dis, 2018. 77(9): p. 1251-1260

[2] Owe, K.M., W. Nystad, and K. Bo, Correlates of regular exercise during pregnancy: the Norwegian Mother and Child Cohort Study. Scand J Med Sci Sports, 2009. 19(5): p. 637-45.

Abstract AB1356HPR Table 1. Level of exercise, BASDAI, VAS pain, VAS fatigue and BMI presented with mean scores and standard deviation (SD)

\begin{tabular}{|c|c|c|c|c|c|c|c|c|}
\hline & & $\begin{array}{c}\text { Before pregnancy } \\
\quad \mathrm{N}=59 \\
\text { Mean (SD) }\end{array}$ & $\begin{array}{c}1^{\text {st }} \text { trimester } \\
N=58 \\
\text { Mean (SD) }\end{array}$ & $\begin{array}{c}2^{\text {nd }} \text { trimester } \\
\quad \mathrm{N}=79 \\
\text { Mean (SD) }\end{array}$ & $\begin{array}{c}3^{\text {rd }} \text { trimester } \\
N=59 \\
\text { Mean (SD) }\end{array}$ & $\begin{array}{c}6 \text { weeks postpartum } \\
N=63 \\
\text { Mean (SD) }\end{array}$ & $\begin{array}{c}6 \text { months postpartum } \\
\mathrm{N}=49 \\
\text { Mean (SD) }\end{array}$ & $\begin{array}{c}12 \text { months postpartum } \\
\mathrm{N}=44 \\
\text { Mean (SD) }\end{array}$ \\
\hline \multirow{5}{*}{$\begin{array}{l}\text { Regular exercisers } \\
\geq 3 \text { times a week }\end{array}$} & & $32,2 \%$ & $19 \%$ & $20,3 \%$ & $8,5 \%$ & $9,5 \%$ & $24,5 \%$ & $13,6 \%$ \\
\hline & BASDAI & $3,0(2,6)$ & $3,0(2,5)$ & $2,9(2,2)$ & $5,5(1,8)$ & $2,9(2,5)$ & $3,4(2,9)$ & $3,2(2,3)$ \\
\hline & VAS pain & $26,2(20,5)$ & $56,8(31,8)$ & $33,4(26,8)$ & $45,4(29,2)$ & $28,5(18,3)$ & $29,9(29,2)$ & $24,8(16,8)$ \\
\hline & VAS fatigue & $38,3(3,8)$ & $36,7(32,9)$ & $50,8(24,5)$ & $57,0(36,4)$ & $42,5(32,6)$ & $33,3(37,4)$ & $29,2(27,1)$ \\
\hline & $\mathrm{BMI}$ & $25,3(4,6)$ & $24,5(2,2)$ & $26,1(2,9)$ & $26,0(2,9)$ & $25,0(2,5)$ & $25,8(5,9)$ & $27,7(7,2)$ \\
\hline \multirow{5}{*}{$\begin{array}{l}\text { Irregular exercisers } \\
\leq 2 \text { times a week }\end{array}$} & & $40,7 \%$ & $46,6 \%$ & $38 \%$ & $35,6 \%$ & $25,4 \%$ & $36,7 \%$ & $34,1 \%$ \\
\hline & BASDAI & $2,9(2,4)$ & $3,4(2,2)$ & $3,2(2,6)$ & $3,2(2,3)$ & $2,5(1,9)$ & $2,3(2,1)$ & $3,3(2,6)$ \\
\hline & VAS pain & $28,1(25,7)$ & $35,4(26,2)$ & $38,8(29,6)$ & $29,4(27,3)$ & $27,4(21,0)$ & $24,7(26,0)$ & $31,8(25,6)$ \\
\hline & VAS fatigue & $40,4(33,5)$ & $59,6(31,3)$ & $53,0(33,5)$ & $52,3(33,8)$ & $35,3(30,3)$ & $27,2(33,5)$ & $41,4(32,5)$ \\
\hline & $\mathrm{BMI}$ & $26,5(7,5)$ & $25,5(4,2)$ & $26,9(4,8)$ & $28,2(4,8)$ & $25,2(3,7)$ & $24,7(3,6)$ & $25,1(3,9)$ \\
\hline \multirow{5}{*}{$\begin{array}{l}\text { Non-exercisers } \\
\leq 3 \text { times a month }\end{array}$} & & $27,1 \%$ & $34,4 \%$ & $41,8 \%$ & $55,9 \%$ & $65 \%$ & $38,7 \%$ & $52,3 \%$ \\
\hline & BASDAI & $4,0(2,2)$ & $3,6(1,9)$ & $2,8(2,1)$ & $3,9(2,6)$ & $3,4(2,7)$ & $4,0(3,1)$ & $3,8(2,6)$ \\
\hline & VAS pain & $42,3(26,7)$ & $34,5(27,4)$ & $31,4(24,5)$ & $42,1(29,8)$ & $36,1(31,0)$ & $37,7(25,3)$ & $34,3(28,3)$ \\
\hline & VAS fatigue & $48,7(29,0)$ & $55,6(36,9)$ & $46,2(30,6)$ & $54,1(29,3)$ & $43,9(33,4)$ & $52,3(30,4)$ & $48,5(35,7)$ \\
\hline & BMI & $26,5(5,1)$ & $27,6(5,8)$ & $27,4(3,9)$ & $30,8(6,1)$ & $26,4(5,2)$ & $26,1(4,9)$ & $24,7(5,7)$ \\
\hline
\end{tabular}


[3] Haglund, E., et al., Differences in physical activity patterns in patients with spondylarthritis. Arthritis Care Res (Hoboken), 2012. 64(12): p. 1886-94.

Disclosure of Interests: None declared

DOI: 10.1136/annrheumdis-2019-eular.1414

\section{AB1357-HPR PROSPECTIVE ANALYSIS OF IRREVERSIBLE ORGAN DAMAGE IN PATIENTS OF KYRGYZ NATIONALITY}

Gulazyk Koilubaeva ${ }^{1}$, Elmira Karimova ${ }^{1}$, Altynai Moldobaeva ${ }^{1}$,

Aijamal Jumakadyrova ${ }^{1}$, on behalf of G. Koilubaeva, E. Karimova, A. Moldobaeva, A. Jumakadyrova. ${ }^{1}$ Togolok Moldo Street, 3, Bishkek, Kyrgyzstan

Background Special attention in recent decades has been paid to the accumulation of irreversible organ effects (SLICC) with systemic lupus erythematosus (SLE) in the form of most diseases, as well as therapy. Along with an increase in survival, the structure of lethal outcomes also changed: cardiovascular pathology, complications of drug therapy, malignant neoplasms, chronic renal and pulmonary insufficiency.

Objectives Study of irreversible organ damage in patients with SLE, prospective observation.

Methods The study included $150(26.31 \%)$ Kyrgyz patients out of 570 with a reliable diagnosis of SLE, female (96\%), young age (median - 34 [26; 44]), Kyrgyz nationality $(89.33 \%)$, high - $61(40.66 \%)$ and very high activity - $40(26.67 \%)$, with the duration of SLE at 1 observation point from 7 months to 10 years, with dynamic observation from 1 year to 3 years. The development of irreversible organ damage was assessed on a scale of damage index (PI) developed by the International Cooperation Organization of SLE Clinics. The absence of damage was rated as 0 points, low $\mathrm{PI}$ - 1 point, average PI from 2 to 4 points, high PI more than 4 points. Results In the Kyrgyz cohort at the initial visit, the absence of irreversible organ damage was observed in the overwhelming majority of patients - in 127 (84.67\%) of 150 . In 1 observation point with organ lesions there were 23 patients (15.33\%) out of 150 , of which with low PI values - 14 (60.87\%), with average values - 9 (39.13\%), there were no patients with high $\mathrm{PI}$ values, due to the small duration of the disease (median - $3[0.7 ; 10]$ of the year). During the initial visit, irreversible organ damage was observed due to the administration of $\mathrm{HA}(8)$ : aseptic necrosis of the femoral heads - in 2, spondylopathy - in 3, cataract - in 2 and diabetes - in 1. Second point of observation was damage to the respiratory organs - 7 patients: pulmonary fibrosis - in 3 and pulmonary arterial hypertension - in 4 . The next in frequency were CNS lesions - in 6 patients: ischemic stroke - in 4 and cognitive impairment - in 2. By the final observation point, organ damage was observed already in $43(28.67 \%)$ patients out of 150 without statically significant progression ( $p>0.05$ ), which in half of the cases were due to the administration of GC - in 24 $(55.82 \%)$ as aseptic necrosis of the femoral heads - in 5, spondylopathy - in 7, cataracts - in 9 and diabetes - in 3. In second place were injuries of the respiratory organs - in 9 (20.93\%) of 43: pulmonary fibrosis - in 5 and pulmonary arterial hypertension (PAH) - in 4. Next in frequency were CNS injuries - in 6 (13.95\%) of 43: ischemic stroke at 4 and cognitive impairments - in the kidneys were observed 2. Damage - $4(9.30 \%)$ of 43 patients: with a reduction in glomerular filtration rate (GFR) in the terminal 3 and the development of CRF 1 as starting severe lupus glomerulonephritis.

Conclusion Under dynamic observation, irreversible organ damage was detected in $28.67 \%$ of cases, which was $13.34 \%$ more compared to the initial state, without statically significant progression ( $p>0.05$ ), mainly due to the administration of $\mathrm{GC}(55,82 \%)$.

Acknowledgement I would like to express my deep gratitude to Professor E. Nosonov and Professor S. Soloviev, my research assistances, for their patient guidance, enthusiastic encouragement and useful critiques of this research work. Disclosure of Interests None declared

DOI: 10.1136/annrheumdis-2019-eular.3900

\section{AB1358-HPR SUICIDAL BEHAVIORS IN PATIENTS WITH INTRAVENOUS BIOLOGIC THERAPIES}

Amparo Lopez Esteban ${ }^{1}$, Roberto Daniel Gonzalez Benitez ${ }^{1}$, Aurora Alonso Amigo ${ }^{2}$, Aurora Alonso Amigo ${ }^{1}$, Juan Carlos Sanchez Zanotti ${ }^{1}$, Florentina García Calle ${ }^{1}$, Juan Carlos Nieto ${ }^{1}$, Belén Serrano Benavente ${ }^{1}$, Juan Ovalles ${ }^{1}$, Tamara Del Río Blasco ${ }^{1}$, Alfonso Ariza ${ }^{1}$, Carlos Gonzalez ${ }^{1}$, Indalecio Monteagudo Sáez ${ }^{1} .{ }^{1}$ Hospital General Universitario Gregorio Marañón, Madrid, Spain; ${ }^{2}$ Psicología Isabel Pinillos, Madrid, Spain

Background: In patients with rheumatic diseases, suicidal ideation (Si) and suicide attempt (Sa) have been observed more frequently than in the general population.

Objectives: 1. To determine the prevalence of $\mathrm{Si}$ and $\mathrm{Sa}$ in patients with biological therapies. 2. To evaluate possible factors associated with the Si.
Methods: Observational cross-sectional study in patients with intravenous BT from Day Hospital of a tertiary hospital in Madrid. Sociodemographic, disease features [weight, height, work disability (WD), diagnosis, treatment] and PRO (FiRST, FACIT-F, HAD, and GHQ-28) were collected. We defined the Si according to the answer at the $6^{\text {th }}$ and $7^{\text {th }}$ questions of section D of the GHQ-28. The Sa was registered according the patient's clinical history. The categorical variables were analyzed with the Chi square test. A logistic regression analysis was performed to evaluate the possible factors associated with suicidal behavior (SB). To evaluate the variance of discrete quantitative variables between groups the Krus kal-Wallis test was used, with a post-hoc analysis with U-Mann Whitney, to determinate the difference between pairs.

Results: We included 321 patients, 65\% women, with a mean age (range, SD) of 56 years $(89-15,14.1)$, and a mean disease duration (range, SD) of 16 years, DS $(53-1,9.7)$. The sociodemographic and clinical characteristics are described in Table 1 and 2. Of all patients, $4 \%$ had had 1 or more $\mathrm{Sa}$ and $11 \%$ had Si. $23 \%$ of patients had associated fibromyalgia (FiRST), 47\% fatigue (FACIT-F), 27.4\% anxiety (A-HAD), $16.2 \%$ depression (D-HAD) and a $48.6 \%$ a probable psychic disorde (GHQ-28). The final logistic regression model includes FACIT-F, IL, D $\mathrm{HAD}$, and first biological with Cox $\mathrm{R}^{2}$ and Snell $20.1 \%$ and Nagelkerke $35.5 \%$. The area under the curve was 0.849 with significance $p<0.0001$ [95\% Cl (0.786 - 0.912)]. Regarding the GHQ-28 score, a significant difference was observed among the diagnostic groups ( $p<0.001)$; in postHoc, a lower score was observed among patients with ankylosing spondylitis $p<0.001$. We also observed a significant difference among the treatment groups $(p<0.001)$ for the GHQ-28 score. In the post-hoc analysis, the Abatacept group had a significantly higher mean $p=0.042$ of GHQ-28 score, however, in the multivariate analysis no significant difference was observed $p=0.416$

Conclusion: There is a high prevalence of $\mathrm{Si}$ and $\mathrm{Sa}$ in patients with BT. Depression, fatigue, sleep disorders, fibromyalgia and work disability were associated with a higher prevalence of SB.

Table 1. Demographic characteristics No ideation/No attempt (273) Ideation (36) Attempt (12)

\begin{tabular}{|l|c|c|c|}
\hline \multicolumn{4}{|c|}{ Table1. Demographic characteristics } \\
\hline & No ideation/No attempt (273) & Idcation (36) & Attempt (12) \\
\hline Gender, \% females & $171(62,6)$ & $28(77,78)$ & $9(75)$ \\
\hline Age [Media(DS)] & $55,8(14,41)$ & $55,8(11,48)$ & $58,7(16,45)$ \\
\hline BMI (DS) & $25,6(4,62)$ & $25,8(4,97)$ & $27,0(4,67)$ \\
\hline Work disability (\%) & $55(20,14)$ & $14(38,88)$ & $6(50)$ \\
\hline Difficulty to sleep (yes) & $136(49,81)$ & $27(75)$ & $8(66,67)$ \\
\hline Disease duration Media (DS) & $15,7(9,89)$ & $17,3(8,81)$ & $13,9(9,15)$ \\
\hline
\end{tabular}

Table 2. Clinical characteristics

\begin{tabular}{lccc}
\hline & No ideation/No attempt (273) & Ideation (36) & Attempt (12) \\
\hline Diagnostic (\%) & & & \\
Rheumatoid arthritis & $125(45,78)$ & $20(55,55)$ & $5(41,66)$ \\
Ankylosing spondylitis & $94(34,43)$ & $6(16.6)$ & $3(25)$ \\
Psoriatic arthritis & $20(7,3)$ & $4(11,11)$ & $0(0)$ \\
Others & $34(12,4)$ & $6(16,6)$ & $4(33,33)$ \\
Treatment (\%) & & \\
Infliximab & $159(58,24)$ & $16(44,44)$ & $3(25)$ \\
Tocilizumab & $46(16,84)$ & $8(22,2)$ & $2(16,67)$ \\
Abatacept & $12(4,3)$ & $6(16,67)$ & $2(16,67)$ \\
Rituximab & $49(17,94)$ & $5(13,88)$ & $5(41,67)$ \\
Others & $7(2,5)$ & $1(2,7)$ & $0(0)$ \\
Previous biologic (yes) & $107(39,19)$ & $25(69,44)$ & $8(66,67)$ \\
FiRST >5 (\%) & $49(17,94)$ & $15(41,66)$ & $9(75)$ \\
FACIT-F < 34 (\%) & $109(39,92)$ & $31(86,11)$ & $11(91,67)$ \\
GHQ-28 >5 (\%) & $114(41,75)$ & $34(94,44)$ & $8(66,67)$ \\
CGHQ-28 >12 (\%) & $216(79,12)$ & $36(100)$ & $11(91,67)$ \\
A-HAD $>11(\%)$ & $61(22,34)$ & $21(58,33)$ & $6(50)$ \\
D-HAD >11 (\%) & $26(9,5)$ & $20(55,55)$ & $6(50)$ \\
\hline
\end{tabular}

Disclosure of Interests: Amparo Lopez Esteban : None declared, Roberto Daniel Gonzalez Benitez: None declared, Aurora Alonso Amigo: None declared, lustina Janta: None declared, Juan Carlos Sanchez Zanotti: None declared, Florentina García Calle: None declared, Juan Carlos Nieto: None declared, Belén Serrano Benavente: None declared, Juan Ovalles: None declared, Tamara Del Río Blasco: None declared, Alfonso Ariza: None declared, Carlos Gonzalez Consultant for: Celgene, Gilead Janssen, Merk, Novartis, Pfizer, Speakers bureau: Celgene, Roche, UCB, Indalecio Monteagudo Sáez: None declared DOI: 10.1136/annrheumdis-2019-eular.6887 